\title{
Metabolic Syndrome: From Human Organ Disease to Fetal Programming
}

\section{Rodrigo Neto-Ferreira ${ }^{1,2}$, Vinícius Novaes Rocha ${ }^{1,2}$, Jorge José de Carvalho ${ }^{2}$, Luiz Carlos Vilanova ${ }^{1}$, Sandra Barbosa-da-Silva ${ }^{3}$ and Vanessa} Souza-Mello

${ }^{1}$ Faculty of Medicine Valença, Experimental Research Center, Valença Superior Education Center, Valença, Rio de Janeiro, Brazil

${ }^{2}$ Laboratory of Ultrastructure and Tecidual Biology, Biomedical Center, Institute of Biology, State University of Rio de Janeiro. Rio de Janeiro, Brazil

${ }^{3}$ Laboratory of Morphometry, Metabolism and Cardiovascular diseases, Department of Anatomy, State University of Rio de Janeiro, Brazil

\begin{abstract}
Metabolic syndrome is defined as a constellation of metabolic disturbances that coexist in a subject. Due to its complex multi factorial etiology, metabolic syndrome causes damage to different organs, representing an increasing and significant global burden. Insulin resistance plays a central role in metabolic syndrome pathogenesis and underpins the majority of metabolic impairments, including the organ diseases that originate from metabolic syndrome. Regarding white adipose tissue, an altered adipokines profile in obesity characterizes a proinflammatory state, which is implicated in the pathogenesis of liver and cardiac disorders. Regarding the liver, nonalcoholic fatty liver disease is a benign disease that can progress towards liver fibrosis in the presence of persistent inflammation and increased oxidative stress. Concerning cardiovascular diseases, adipokines, reactive oxygen species and over activity of the renin angiotensin system play central roles. Another target organ of metabolic syndrome is the ovary, where polycystic ovary syndrome is also related to insulin resistance and can originate from adverse intrauterine conditions. The notion that maternal obesity can trigger metabolic syndrome in the fetus is alarming, given that it can be passed to other generations even if adequate nutrition is provided after birth. This review aimed to assess the main outcomes of metabolic syndrome in white adipose tissue focusing on insulin resistance and adipokines, the cardiovascular system, the liver and ovaries as well as fetal origins; this review also discusses some proposed pharmacological treatments to provide a better understanding of the related pathways in these secondary findings.
\end{abstract}

Keywords: Metabolic syndrome; Adipokines; Insulin resistance; NAFLD; Cardiovascular diseases; Maternal obesity; Polycystic ovaries syndrome

\section{Introduction}

Metabolic Syndrome (MS) is defined as a constellation of metabolic disturbances that coexist in a subject [1]. In 1988, Reaven first described MS as being characterized by the combination of Insulin Resistance (IR) and compensatory hyperinsulinemia, high levels of plasma triglycerides, low plasma levels of High Density Lipoprotein (HDL) and hypertension, all of which lead to a higher risk of cardiovascular diseases [2].

Due to its complex multifactorial etiology, MS causes damage to different organs, representing an increasing and significant global burden [3,4]. MS affects approximately $20 \%$ of the adult population in developed countries and at least $80 \%$ of people with type 2 Diabetes mellitus (T2DM) [5,6]. IR, which plays a central role in MS pathogenesis and underpins the majority of metabolic impairments, is associated with systemic inflammation and reduced adiponectin levels $[7,8]$. Recently, it has been widely accepted that MS has an intrauterine origin, given the increasing number of obese pregnant women with unhealthy eating habits $[9,10]$.

The following secondary findings are often associated with MS: nonalcoholic fatty liver disease (NAFLD), polycystic ovary syndrome (PCOS), enhanced oxidative stress and endothelial dysfunction [1]. Adipokines, which are produced and released by White Adipose Tissue (WAT), play a pivotal role in the course of these secondary findings of MS and are implicated in IR development, in lipotoxicity and in the consequent ectopic fat deposition [7,11]. This review also aimed to assess the main MS outcomes in WAT (focusing on IR and adipokines), the cardiovascular system, the liver and ovaries as well as fetal origins and some proposed pharmacological treatment to provide a better understanding of the related pathways in these secondary findings.

\section{Adipose Tissue, Insulin Resistance and Adipokines}

\section{Adipose tissue}

It is widely accepted that adipose tissue is a highly dynamic endocrine organ that secretes more than 600 bioactive substances termed "adipokines" and plays an essential role in regulating insulin sensitivity, energy metabolism and vascular homeostasis [12]. It has become clear that obesity promotes a state of chronic low-grade systemic inflammation in WAT. This chronic inflammation is deeply involved in IR, which is the underlying condition of T2DM and MS [13]. An inflammatory state develops in response to excessive nutrient influx into metabolic tissues including adipose tissue, liver, and skeletal muscle and is currently recognized as an important link between obesity and IR [14].

Obesity results in excessive lipid accumulation in adipocytes and macrophages in WAT, which plays an active role in the development of IR through the release of Free Fatty Acids (FFAs), proinflammatory cytokines, and adipokines. Moreover, an increase of adipose tissue mass not only increases IR in obese subjects, but it is also closely related to abnormal glucose metabolism [15].

Ectopic fat deposition occurs when adipose tissue cannot expand further to store excess nutrients. Thus, lipid accumulates in other tissues, leading to IR, cardiovascular complications and other lipotoxic effects such as apoptosis [16]. There is marked expansion of WAT, primarily indicated by adipocyte hypertrophy or enlargement due to an increased rate of lipolysis coupled with decreased lipid oxidation [17]. These conditions maximize pro-inflammatory cytokine secretion and the risk of IR [18].

*Corresponding author: Rodrigo Neto-Ferreira, FAA - Fundação Educacional D. André Arcoverde, Centro de Ensino Superior de Valença. Address: R. Sargento Vítor Hugo, n 161 | Fátima - Valença / RJ, CEP: 27600-000, Tel: 5524 2453-0712; E-mail: rodrigonetoferreira@gmail.com

Received February 01, 2014; Accepted February 25, 2014; Published March 05 2014

Citation: Neto-Ferreira R, Rocha VN, de Carvalho JJ, Vilanova LC, Barbosa-daSilva S, et al. (2014) Metabolic Syndrome: From Human Organ Disease to Fetal Programming. J Metabolic Synd 3: 133. doi:10.4172/2167-0943.1000133

Copyright: $(2014$ Neto-Ferreira R, et al. This is an open-access article distributed under the terms of the Creative Commons Attribution License, which permits unrestricted use, distribution, and reproduction in any medium, provided the original author and source are credited. 


\section{Insulin resistance}

Obesity and IR are the main hallmarks of MS; IR is a complex metabolic disorder, whose pathways are closely linked to changes in fatty acid uptake, lipogenesis, and energy expenditure, causing ectopic lipid deposition and the activation of the Unfolded Protein Response (UPR); the UPR regulates lipogenesis, allowing the expansion of the ER membrane and increasing the capacity of the ER to handle proteins. Moreover, in adipose tissue, UPR activation appears to regulate energy balance. Accordingly, activation of the UPR may primarily alter cellular lipid balance and, via the accumulation of lipid intermediates, alter insulin signaling [19]. IR is a major underlying feature of T2DM and is often linked to obesity and many other chronic metabolic abnormalities, including dyslipidemia, NAFLD, polycystic ovary syndrome, and hypertension [20,21].

Excessive adipose tissue plays a central role in the initiation of IR [22]. When there is IR in adipose tissue, adipocytes tend to hypertrophy and their appropriate physiological functions are inhibited [23]. Elevated circulating FFAs levels lead to increased availability of these lipids in peripheral organs such as muscle and liver [24]. Despite its multifactorial etiology, IR is highly influenced by adipokine secretion. Therefore, this review will focus on this relationship.

\section{Adipokines and insulin resistance}

Adipokines are active multiple metabolically important proteins secreted by adipose tissue [25]. Dysregulation of adipokines is recognized as a common factor in IR and MS [26]. Adipokines provide an important link between IR and obesity. Inflammation and adiposity cause IR by interfering with insulin signaling. The adipokines exert their effects on paracrine and/or autocrine signaling and contribute to the modulation of adipogenesis [27]. The obese adipose tissue is characterized by adipocyte hypertrophy and infiltration of inflammatory macrophages and lymphocytes, leading to the augmented production of pro-inflammatory adipokines, with proatherogenic effects and worse metabolic profile, including alterations in the levels of the leptin, resistin, IL-6 and TNF-alfa, visfatin, RBP-4 [26].

Adiponectin is highly and specifically expressed in differentiated adipocytes and circulates at high levels in the bloodstream [28]. Adiponectin provides the required link between obesity and IR [29]. The insulin sensitivity, which is reduced in obese individuals, is improved by the actions of adiponectin. Adiponectin is an adipokine with insulin sensitizing and anti-inflammatory activities and exerts beneficial effects on metabolic and vascular functions. However, its production is severely reduced with obesity, and it is a unique adipokine in that its levels are inversely related to MS [12,30]. Adiponectin expression is higher in subcutaneous tissue than in visceral adipose tissue [31]. Adiponectin is also anti-inflammatory; it suppresses Tumor Necrosis Factor (TNF) actions in NAFLD and inhibits NFkB and monocyte adhesion to endothelial cells [32]. In mice with transgenic overexpression, adiponectin was shown to have anti-obesity effects due to enhanced energy expenditure and impairment of adipocyte differentiation [33].

Resistin was identified as an adipokine in 2001 and is highly expressed in abdominal WAT [34]. Resistin is secreted primarily by adipocytes in rodents and was initially proposed as a link between obesity and IR in rodents however, it is expressed and secreted from macrophage immune cells in humans and is increased under inflammatory conditions [7,34-36]. Studies relating human resistin to IR or T2DM have produced conflicting results nevertheless, the prospective case-control studies have shown that people with elevated baseline levels of resistin have significantly increased risk of developing T2DM, even after adjusting for other risk factors [37,38].

Leptin was the first of the adipokines discovered to play a role in the modulation of adiposity [39]. It is almost exclusively secreted from adipocytes, controls food intake and energy expenditure and has antiatherogenic and growth properties. Obesity is associated with increased leptin serum concentrations, which potentially contribute to the development of IR and MS [40]. In addition to its potential role as a mediator of IR, leptin has been identified as an important regulator of $\beta$-cell mass and cell survival [41]. Studies in leptin receptor-deficient Zucker Diabetic Fatty (ZDF) rats revealed that the reduction in $\beta$-cell mass is primarily due to an increased rate of $\beta$-cell death and is not related to proliferation [42].

Retinol-binding protein-4 (RBP-4) was established as an adipokine in the 1990s and has been proposed to modulate systemic insulin sensitivity, being linked to inflammation IR, T2DM, dyslipidemia and similar metabolic abnormalities [43-45]. The RBP-4, a $21 \mathrm{kDa}$ protein, is predominantly secreted by the liver but is also expressed in adipocytes [46]. However, increased RBP-4 serum concentrations have been shown to be the result of increased RBP- 4 expression in visceral adipose tissue in patients with IR [47]. Increased circulating RBP4 concentrations has gained a lot of attention after first being shown in the serum of insulin resistant humans and mice in several metabolic complications such as obesity, IR, MS and abdominal fat distribution $[47,48]$.

Tumor necrosis factor-alpha (TNF- $\alpha$ ) is a potent proinflammatory cytokine and was the first WAT-derived inflammatory cytokine reported to be implicated in the initiation and progression of IR [49]. A key mechanism by which TNF- $\alpha$ induces IR involves the phosphorylation of Insulin Receptor Substrate-1 (IRS-1) [50]. Apart from its direct negative interference with insulin signaling pathway, TNF- $\alpha$ also indirectly induces IR by altering adipocyte differentiation and adipocyte lipid metabolism. TNF- $\alpha$ is known to promote lipolysis and the secretion of FFAs, which contribute to an increase in hepatic glucose production [51].

Monocyte chemo attractant Protein-1 (MCP-1) is one of the key chemokines that regulate migration and infiltration of monocytes/ macrophages into sites of inflammation. It is expressed and secreted by adipose tissue [52] and acts through its receptor CCR2. The interaction between MCP-1 and its receptor CCR2 is pivotal in obesity-induced IR. Several studies have reported that mice with targeted deletions in the genes for $\mathrm{Mcp}-1 / \mathrm{Ccl} 2$ and its receptor Ccr2 have decreased adipose tissue macrophage content, decreased inflammation in the fat tissue, and protection from High-Fat (HF) diet-induced IR [53]. Adipose tissue expression of MCP-1 and circulating MCP-1 levels are increased in rodent obesity, suggesting that MCP-1- mediated macrophage infiltration of adipose tissue may contribute to the metabolic abnormalities associated with obesity and IR [54].

Apelin (also known as APJ receptor ligand) is a peptide that has been recently identified and is secreted by both human and mouse WAT $[55,56]$. It acts as an adipokine and plays a role in the regulation of glucose homeostasis; it may contribute to the link between increased adipose tissue mass and obesity related metabolic diseases. In humans, evidence of apelin regulation in the presence of impaired glucose metabolism is still controversial; apelin serum concentrations were shown to be higher in patients with obesity and IR [57]. On the other hand, other authors reported low apelin levels in obese subjects with newly diagnosed T2DM compared to non-diabetic individuals. Apelin serum concentrations correlate with hyperinsulinemia and obesity, suggesting that apelin may be another adipokine that mediates impaired adipose tissue function in obesity [57]. 


\section{NAFLD and NASH}

In the last two decades, NAFLD and nonalcoholic steatohepatitis (NASH) have become the most common cause of liver disease in Western countries. NAFLD worldwide distribution is closely associated with diabetes and obesity, two conditions that have reached epidemic proportions in both rich countries and poor countries, affecting public health worldwide. It is estimated that for the next 5 years, NAFLD will increase by $26 \%$, causing direct and indirect public health consequences [58]. NASH is the most severe histological form of NAFLD and is characterized by excessive accumulation of fat in triglyceride form (steatosis) in the liver (histologically above $5 \%$ of hepatocytes). While simple steatosis observed in NAFLD does not involve increased morbidity and mortality in the short term, the progression of this condition to NASH dramatically increases the risk of cirrhosis, liver failure, and hepatocellular carcinoma. In general, steatohepatitis is considered to be the hepatic expression of MS associated with diseases such as T2DM, IR, central obesity, dyslipidemia and hypertension. Hepatic lipid accumulation in NAFLD results from disturbances in lipid homeostasis and may contribute to the progression of NASH. It was previously described that high FFAs from lipolysis in WAT induces lipid accumulation in the liver through the activation of hepatic lipogenesis including de novo synthesis of FAs [59].

FA synthesis is catalyzed by acetyl-CoA carboxylase (ACC) and fatty acid synthase (FAS), and these enzymes are regulated by nuclear receptors including peroxisome proliferator-activated receptors (PPARs) and sterol regulatory binding protein-1 (SRBP1). Increased hepatic ceramide has been associated with progression of NAFLD; ceramides are members of the family of sphingolipids with important roles in cell signaling. Numerous routes have been correlated with the progression of NAFLD ceramides. Specifically, hepatic inflammation, in which ceramide leads to the emergence of mitochondrial dysfunction and an increase in ROS levels [60]. The increased generation of ROS may trigger an apoptotic process in hepatocytes, and consequently, the recruitment of inflammatory cells to the liver, leading to the emergence of a vicious cycle that amplifies hepatic inflammation. The elevated synthesis of lipogenic enzymes demand overwork by the Endoplasmic Reticulum (ER), leading to the condition known as ER stress. ER stress can also exacerbate lipid accumulation by the activation of lipogenesis through SRBP1. As we already know, NAFLD and T2DM have common pathological mechanisms. Thus, antidiabetic agents (especially insulin sensitizers) and lipid lowering drugs play a pivotal role in treating NAFLD or reducing its progression [61].

\section{Insulin sensitizers}

One of the most used drugs that will be addressed in this review is metformin, which exhibits beneficial effects on lipid and glucose metabolism. At the molecular level, it inhibits the mitochondrial respiratory chain, leading to a transient decrease in energy. This fact promotes cell activation of adenosine monophosphate-activated protein kinase (AMPK), resulting in the inhibition of gluconeogenesis and hepatic lipogenesis, increased glucose uptake in muscle and increased the fatty acid oxidation in the liver [61].

AMPK plays a central role as a regulator of cellular metabolism, which consists of a heteromeric complex catalyst consisting of three subunits: alpha, beta, and gamma. Because of its ability to regulate cellular metabolism, modulation of AMPK has become an important therapeutic target in NAFLD. Various drugs have been used in the treatment of type 2 diabetes [61]. However, as already mentioned above, metformin has been effective at altering the AMPK signaling pathway, resulting in the improvement of hepatic steatosis and fibrosis.
The mechanism by which the AMPK pathway is induced by insulin sensitizers demonstrates the specificity of these drugs in the alteration of mitochondrial function by binding to mitochondrial complex I, thereby converting ADP to ATP / AMP and inducing AMPK [62].

Clinical trials show conflicting results, providing evidence that metformin improves metabolic features of NAFLD and may be useful in the long term in patients with NAFLD [63]. However, more clinical studies are necessary to ensure the effectiveness of this drug in modifying the natural history of NAFLD.

\section{Thiazolidinediones (TZDs)}

Thiazolidinediones sensitize cells to insulin (Yki-Jarvinen, 2004) and include troglitazone, rosiglitazone and pioglitazone [61]. The first two TZDs have been withdrawn from the market because of their significant side effects, while pioglitazone has been indicated for diabetes treatment in humans. TZDs act as agonists of the PPAR $\gamma$, which is a member of the superfamily of nuclear receptors that activates the transcription of specific genes and is highly expressed in adipocytes and other tissues [64]. TZDs also activate AMPK and inhibit lipolysis. Pioglitazone was effective in the treatment of NAFLD by reducing hepatic steatosis. Clinical trials with pioglitazone have shown beneficial effects, showing a great promise in the treatment of NAFLD. These substances have been used in the treatment of T2DM to improve IR by direct and indirect effects on hepatic tissue such as altering the secretion of adipokines (decreased TNF- $\alpha$ and increased adiponectin) and the consequent improvement of insulin sensitivity in the liver $[65,66]$.

\section{GLP1 analogues}

Glucagon-Like Peptide1 (GLP1) and glucose-dependent insulinotropic polypeptide (GIP) are two peptides, known as incretins, which are secreted from the gastrointestinal tract in response to certain nutrients, especially glucose. The incretins also inhibit glucagon secretion, contribute to the inhibition of hepatic glucose output and have antiproliferative effects on beta cells. The GLP1 has a very short half-life (1-2 min) due to rapid degradation by the enzyme, Dipeptidyl Peptidase 4 (DPP-4). There are two medicines known as incretin mimetics, exenatide and liraglutide, which are commonly used in T2DM. These drugs are GLP1 analogs and are resistant to degradation by DPP4, exhibiting a long half-life [61].

\section{DPP4 inhibitors}

DPP4 is a ubiquitous enzyme that is expressed in all organs including the small intestine, biliary tract, exocrine pancreas, spleen and brain. This widespread organ distribution indicates that the DPP4 affects multiple biological processes, such as in the regulation of glucose metabolism, intestinal motility and appetite regulation. DPP4 inhibitors are used to treat T2DM due to their ability to increase the circulating levels of GLP1 [67]. Experimental evidence showed that sitagliptin, alone or combined with telmisartan, markedly reduced hepatic steatosis in a diet-induced obesity mouse model. It acted through enhanced hepatic beta-oxidation, reduced hepatic lipogenesis and increased density of mitochondria per area of hepatic tissue [63]. Several DPP4 inhibitors are already used in medical practice; these include alogliptin, saxagliptin, sitagliptin and vildagliptin. Patients with NAFLD have high liver levels of DPP4 compared to healthy individuals. Furthermore, the activity of serum DPP4 and liver DPP4 expression are negatively correlated with the degree of NAFLD [61].

\section{Statins}

Statins are the drugs that are most commonly used for the treatment 
of hyperlipidemia for primary and secondary prevention. These effects are a result of the inhibitory activity of statins on the enzyme hydroxymethylglutaryl CoA (HMG-CoA) reductase; statins block the conversion of the HMG-CoA substrate to mevalonic acid by inhibiting the early steps of cholesterol biosynthesis [68].

Rosuvastatin is a new statin family member with greater efficacy at lowering LDL cholesterol that other statins at comparable doses [69]. Rosuvastatin was shown to have a greater number of interactions by binding to HMG-CoA reductase compared to other statins. Moreover, rosuvastatin also has a relatively long half-life and a high degree of selectivity for liver cells (primary site of cholesterol synthesis) compared with non-liver cells [70].

Recent investigations have shown several important effects of statins, such as anticancer action, inhibition of bone reabsorption and increased availability of endothelial nitric oxide [71]. Recent studies have shown that statins have additional effects, with improvement in hepatic insulin sensitivity in animal models of diet-induced obesity and in humans $[58,59]$. Given the pivotal role that IR exerts upon NAFLD development, beneficial hepatic outcomes are achieved with statin therapy. Our recent study showed that treatment with rosuvastatin promoted marked reduction in the hepatic expression of SREBP-1c, with decreased hepatic lipogenesis and reduced hepatic steatosis in an animal model of obesity [58]. However, the use of statins as a strategy in the treatment of IR and hepatic steatosis has not been extensively investigated.

\section{Cannabinoid receptors}

The cannabinoids exert their effects through two different cannabinoid receptors (CB1 and $\mathrm{CB} 2$ ), both of which are $\mathrm{G}$ proteincoupled. These receptors are involved in the development of hepatic fibrosis. Thus, studies have shown that marijuana use can be correlated with the progression of liver fibrosis. However, each receptor has different functions in the liver. The $\mathrm{rCB} 1$ and $\mathrm{rCB} 2$ are heavily involved in the progression of hepatic fibrosis [72]. Studies have shown that rCB1 antagonists have a significant effect in reducing liver fibrosis as well as in reducing body weight and in cardiac and metabolic parameter improvement in obese patients. Experimental and clinical data indicate that the activation of peripheral CB1 receptors promotes IR and hepatic steatosis; these findings pivotal in the development of NAFLD. Thus, the use of CB1 antagonists in the treatment of NAFLD and NASH may be a suitable approach [73].

\section{Other agents}

A new drug used to target T2DM is called ipraglifozin (sodiumglucose cotransporter type 2 inhibitor in the kidneys), which was recently approved as an oral treatment of T2DM. A recent study in an experimental model investigated the effect of this new drug class on mice liver. It demonstrated a significant reduction in the markers of oxidative stress in the liver, resulting in significant improvement of liver enzymes after 4 weeks of treatment. Nevertheless, studies in humans are crucial for validating these findings [74].

There is neither established treatment nor clinical evidence-based guidelines for the treatment of NAFLD and NASH. It is believed that more experimental and clinical studies are needed to better understand the natural history of NAFLD [74].

\section{Cardiovascular Diseases}

A number of studies have reported that MS, a group metabolic risk factors, increase the risk for cardiovascular disease [75-79].
Nordestgaard and Thomsen (2013) attached greater importance to overweight and obesity as risk factors for myocardial infarction and ischemic heart disease, regardless of the presence or absence of MS [80]. MS is defined as 3 or more of the following metabolic abnormalities: hypertension, dyslipidemia (hypertriglyceridemia and low levels of high-density lipoprotein cholesterol), increased waist circumference and diabetes mellitus (DM) $[6,80,81]$. Currently, the pro-inflammatory and pro-thrombotic states are also considered to be components of MS [82-84].

Emerging evidence supports MS as a condition that favors adverse cardiac remodeling, which might evolve towards heart dysfunction and failure. This pathological remodeling has been implicated in the cardiac adaptive response to hypertension, dyslipidemia, and hyperglycemia coupled with inflammatory molecules and hormones [85]. The mechanisms underlying cardiac dysfunction in MS are complex and might include lipid accumulation, increased fibrosis and stiffness, altered calcium homeostasis, abnormal autophagy, altered substrate utilization, mitochondrial dysfunction and increased oxidative stress [86-88].

Several intracellular signaling pathways have been investigated to characterize their role in cardiomyocyte modifications and potential injury associated with MS. Some hormones, such as aldosterone, angiotensin and insulin, as well as cytokines, such as Tumor Necrosis Factor (TNF) and Interleukin-6 (IL-6), have been shown to be potent inducers of cardiovascular alterations as well as cardiac fibrosis and cardiac hypertrophy $[85,88,89]$. Some studies have also reported the same components in MS, thus suggesting a possible link between mediators of cardiovascular disease and MS [85,86,89-91].

The hormones, angiotensin and aldosterone, are part of the reninangiotensin-aldosterone system. The deleterious effects of angiotensin II are initiated after coupling with type 1 receptors. The type 1 receptor coupling activates protein kinase $\mathrm{C}$ and c-Src pathways. The activation of these pathways triggers the activation of NADPH oxidase (Noxl and NOX2). The activation of these redox-dependent pathways produces reactive oxygen species. This leads to pathophysiological effects of angiotensin II, which include mitogenic, proinflammatory and profibrotic actions. In addition to the direct action on the heart, angiotensin II stimulates the formation of aldosterone in the adrenal gland. The action of aldosterone in cardiac cells is mainly related to the activation of mineralocorticoid receptors that can increase the cardiac $\mathrm{Na}+/ \mathrm{H}+$ exchanger (pathway src-kinase phosphorylation and subsequent recruitment and activation of metalloproteinase receptor epidermal growth factor), contributing to hypertrophy of the heart. Moreover, the activation of aldosterone receptors can enhance the automaticity of the cardiomyocytes, generating atrial and ventricular arrhythmias through increases in the transcription of the voltage-gated T-type calcium channel [92-96].

Insulin resistance and hyperinsulinemia have been correlated with an increased risk of heart failure. A high glycemic load stimulates insulin secretion and activation of insulin-signaling pathways, stimulating protein synthesis and decreasing protein breakdown, and might act as a growth factor in the heart, which could induce fibrosis, reactive oxygen species, and apoptosis, driving the development of heart failure. In addition, insulin may also play a key role in regulating fatty acid uptake via CD36 translocation, and the myocardial insulin resistance may specifically predispose cardiac mitochondria to reactive oxygen species [88,97-99].

The hemodynamic effects of Tumor Necrosis Factor (TNF) are characterized by decreased myocardial contraction, reduced 
ejection fraction and ventricular dilatation. TNF alters the influx of calcium through the calcium channels, which are responsible for excitation-contraction. Furthermore, TNF induces apoptosis through a sphingosine-dependent mechanism or by interaction with specific proteins such as TRADD. TNF- $\alpha$ has also known to up-regulate IL-6 through a gp130 receptor ligand interleukin (IL)-6. It is believed that IL-6 activates a cardiac hypertrophic program through Janus kinase/ signal transducers $[100,101]$.

MS has also been linked to oxidative stress, a consequence of a reduction in the antioxidant systems and an increase in the production of reactive oxygen species [102-104]. Just as in MS, numerous cardiovascular diseases are related to oxidative stress. The mechanisms for increased cardiac oxidative stress in MS are not fully understood but increased fatty acid oxidation, mitochondrial dysfunction and enhanced NADPH oxidase activity may be involved $[87,105,106]$. A major source of reactive oxygen species involved in both MS and cardiovascular pathophysiology is the NADPH oxidase enzyme [107].

The contribution of ROS to the development of heart disease may be related to physical damage to the cellular and mitochondrial structures. Because the majority of ROS in heart failure originates from mitochondria, these organelles are the primary target of oxidative damage and, consequently, mitochondrial dysfunction. The activities of the mitochondrial electron transport chain are suppressed in heart failure, and disruption of mitochondrial bioenergetics function was found to increase ROS and oxidative DNA damage, providing a possible pathophysiological link between mitochondrial dysfunction and ROS. In addition to damaging cellular components, ROS regulate several signaling cascades, including the known hypertrophic pathways such as protein kinase $\mathrm{C}$, mitogen-activated protein kinase, Jun $\mathrm{N}$-terminal kinase, and Ras [88,108-111].

Balderas-Villalobos et al. (2013) demonstrated an important role of elevated reactive oxygen species levels upon depressed SERCA activity in cardiomyocytes, which, in turn, has been reported to affect cardiac function [112]. The authors explain this event by the fact that elevated production of ROS in metabolic syndrome myocytes is paralleled by prolonged electrically stimulated $\mathrm{Ca}$ transients and slowed SERCAmediated sarcoplasmic reticulum Ca reuptake. In addition, treatment of MS myocytes with an antioxidant agent normalizes ROS production and SERCA2-mediated sarcoplasmic reticulum Ca2 reuptake [112].

Another potential mechanism for cardiac insufficiency in MS is the oxygen wasting due to energy use for noncontractile purposes through uncoupling protein activation, which increases the reactive oxygen species production and, subsequently, oxidative stress. Mitochondrial dysfunction has been identified in a number of models of obesity and diabetes, suggesting that compensatory mechanisms eventually become maladaptive $[97,105]$. The interaction between the components of MS contributes to the development of a pro-inflammatory state, which leads to endothelial dysfunction, enhanced recruitment of monocytes within the arterial wall and the formation of unstable atherosclerotic plaques $[113,114]$. MS and most of its components are associated with a higher prevalence of calcified atherosclerotic plaques in the coronary arteries and abdominal aorta and its diagnosis was significantly correlated with arteriosclerosis in all regions, including the cerebral small-vessels, extra-cranial carotid arteries, coronary arteries and abdominal aorta $[115,116]$.

The vascular damage appears to be derived from a variety of changes in the adipose tissue due to MS, leading to a chronic inflammatory state. This, in turn, impairs vascular homeostasis by determining an unbalance between the protective effect of the nitric oxide pathway and the unfavorable action of the endothelin-1 system [91,117]. The vascular dysfunction in obesity is not only limited to the endothelium but it also can involve the intimal and the adventitial layers. In the latter, the perivascular fat appears to be a source of pro-inflammatory and vasoactive factors that may contribute to endothelial and smooth muscle cell dysfunction [117].

Stepp et al. (2013) reported evidence of the microvascular remodeling in MS models. This remodeling is characterized by reduced lumen size, atrophy of the vascular wall and differentiation of the vascular smooth muscle, leading to vascular structure damage [118]. Kuliszewski et al. (2013) demonstrated that, in the presence of MS and DM, bone-marrow-derived endothelial progenitor cells develop similar marked functional impairment. Bone-marrow-derived endothelial progenitor cells represent one subset of progenitor cells and are mobilized to the postnatal circulation. These cells can differentiate into mature endothelial cells and, under tissue injury, facilitate vascular repair and tissue regeneration. The functional impairment of these cells limits their ability to restore perfusion to ischemic muscle and similar mechanisms may underlie the defective endothelial repair observed in cardiometabolic diseases and thus contribute to the increased cardiovascular risk in these populations [119].

In a more critical analysis, each component of MS may contribute directly or indirectly to the development of cardiovascular diseases, and their combination carries additional risk. This strong relationship may hinder the understanding of the underlying mechanisms. Further studies are needed to better understand the relationship between the signaling pathways of MS and cardiovascular disease and may thus help identify the best treatment approaches.

\section{Polycystic Ovary Syndrome}

PCOS is characterized as a state of hyperandrogenism coupled with disordered gonadotropin secretion, which compromises follicle development in the ovaries; this phenomenon leads to menstrual irregularities, which can lead to infertility if they are not properly addressed [120]. PCOS affects approximately 5-10\% of women of childbearing age and is often associated with IR and obesity; it is diagnosed in $28 \%$ of obese women and in only $5 \%$ of lean women $[121,122]$.

PCOS has been proposed to be the ovarian manifestation of MS as it is closely related to IR and NAFLD, two hallmarks of MS [123,124]. Insulin receptors are ubiquitously expressed in the ovaries, which under abnormal insulin signaling in theca cells, yields increased androgen synthesis [125]. PCOS symptoms, such as hirsutism and menstrual disorders, are more evident in obese women who have larger fat pads that have a higher pancreatic demand for insulin, which results in hyperinsulinemia [126]. This condition usually compromises translocation of the glucose transporter to the membrane due to serine phosphorylation of the insulin receptor $\beta$-subunit, which results in the inhibition of tyrosine residue autophosphorylation, causing reduced AKT phosphorylation $[127,128]$. Despite being more pronounced in obese women, even lean women with PCOS exhibit IR [129].

PCOS pathogenesis is multifactorial, and some evidence suggests that it is influenced by intrauterine exposure to excessive androgens [130]. It impairs the Hypothalamic-Pituitary-Ovarian (HPO) and hypothalamic-pituitary adrenal (HPA) axes, favoring the PCOS phenotype, which includes IR, hyperandrogenism, excessive luteinizing hormone secretion and reduced ovulation [131-133]. Likewise, postnatal factors are also implicated in this complex pathogenesis: the association between low birth weight and rapid catch-up growth, premature menarche and sustained augmented visceral fat pad, the main predictors of PCOS in young girls [130,134]. 
Regarding treatment, lifestyle modifications and drugs that alleviate other components of MS are usually efficient in PCOS management [135]. Metformin emerges as the most powerful, low-cost and effective approach in controlling PCOS and reducing infertility in adolescents and adult patients once these patients have IR. By reducing hepatic production of glucose, it lowers insulin secretion and restores the menstrual cycle, ovulation and fertility, given that hyperinsulinemia impairs HPO axis functioning [136-139].

\section{Fetal Programming}

Considering that the current obesity epidemic is a public health concern and encompasses different economical classes and age groups the resulting comorbidities and metabolic impairments might threaten future generations $[3,140]$. Among women, approximately one third of pregnant women are obese in the USA. Thus, the maternal diet has been proposed as a cornerstone of adequate morphological and physiological fetal development, and excessive fat intake has been highly associated with gestational DM and hypertensive disorders. Moreover, offspring from obese mothers is usually heavier and more prone to develop the MS components in adult life [141-143].

Recent studies have shown that the intrauterine milieu plays a crucial role in obesity pathogenesis, being as important as postnatal environmental factors [144]. Maternal health and nutritional status during gestation and lactation have long lasting effects upon central and peripheral systems that regulate energy balance in offspring [143]. A maternal diet rich in glucose, fatty acids and amino acids causes a predictive adaptation in the fetus once the developing organism considers the maternal diet as an indicator of the postnatal environment. Thus, permanent changes in fetal homeostasis with impairments in appetite control and neuroendocrine metabolism appear to be an attempt to guarantee fetal survival under a most likely adverse postnatal environment. These modifications in energy homeostasis circuits imprint obesity in adult life of the fetus [144-146].

From the moment of conception, embryo physiology begins to be defined according to intrauterine conditions. The pattern of cellular division of the embryo is orchestrated by the amount and quality of nutrients obtained through the placenta. Fetal demands that are not fulfilled due to maternal malnutrition can alter fetal growth trajectory, causing future multiple complications [147-149].

Experimental studies show that hyperphagia precedes obesity in the offspring of high-fat feeding dams, indicating hypothalamus programming $[145,150,151]$. Insulin appears to exert a huge influence upon hypothalamic programming as a previous study shows that insulin injections during gestation induce obesity in offspring. Likewise, leptin plays a crucial role in the promotion of appetite and energy balance [152]. The interplay between insulin and leptin, the so-called adipoinsular axis, is impaired in male offspring from pregestational obese dams [144,153]. Male offspring exhibited IR and hyperinsulinemia at 3 months old, which blocked the capacity of leptin to reduce insulin secretion at the postprandial state. Consequently, hyperleptinemia developed, and the resulting hyperphagia and positive energy balance lead to obesity [153-155].

Concerning pancreatic alterations, maternal intake of a high-fat diet during specific periods of gestation and/or lactation programs the physiology and metabolism of this organ with early life consequences [156]. Hyperglycemia and impaired development of pancreatic beta cells were observed in rat pups programmed with a high-fat diet during gestation [157]. In addition, maternal diet during gestation is more harmful to the pancreas than during the lactation period. Altered maternal nutrition during gestation increased beta cell mass and alpha cell mass followed by IR, islet hypertrophy and altered islet architecture and is as deleterious as a maternal high-fat diet during all of gestation and lactation [158]. High-fat programming during gestation impairs insulin secretion and reduces the immunoreactivity of $\mathrm{Pdx} 1$, which is essential for beta-cell differentiation. In the long term, these conditions can lead to beta cell failure and DM [159].

Gestational DM can occur due to prediabetes prior to pregnancy or glucose intolerance during gestation, which is caused by augmented placental transport of glucose, insulin and other nutrients from the mother to the son [160]. Gestational DM causes expressive maternal hyperglycemia, which is followed by disorganization of beta cell cytoarchitecture and its secretory failure [161]. The combination of a diabetogenic tendency and metabolic stress during gestation can result in gestational DM and this mechanism can be transmitted from one generation to another [162].

Excessive maternal nutrition also causes adverse hepatic remodeling as obesity and IR act as cornerstones in NAFLD development [163]. Enhanced lipolysis in adipose tissue from obese subjects generates FFAs that are directed to the liver, whereas IR favors hepatic lipogenesis and reduces hepatic oxidation of fats. These alterations cause hepatic accumulation of lipids, which impair liver function and structure [164]. Maternal high-fat feeding caused higher rates of hepatic steatosis with reduced expression of PPAR-alpha and increased expression of SREBP-1, consistent with impaired beta-oxidation and higher lipogenesis [165]. Pre-conception maternal obesity seems to maximize hepatic alterations as mitochondrial dysfunctions such as the reduction of carnitine palmitoyltransferase I (CPT-1) and fatty acid translocase (FAT)/CD36 expressions were exhibited by the offspring, implicating the insufficient transport of fatty acids across mitochondrial membranes. The activation of different PPAR isoforms by Bezafibrate in adult offspring addressed all hepatic features of maternal obesity, emerging as a beneficial and suitable approach [166].

\section{Conclusions}

Overall, there is still no consensus on a precise MS definition as it is difficult to compare different populations worldwide. However, even if parameters for diagnosis differ among different ethnic groups or continents, the mechanisms by which IR and altered adipokine profile underpin the secondary findings are the same. This knowledge is essential for a suitable screening for MS and is crucial for the establishment of a more straightforward approach, minimizing the constraints of MS for the patient and drastically reducing treatment costs.

\section{Reference}

1. Eckel RH, Grundy SM, Zimmet PZ (2005) The metabolic syndrome. Lancet 365: $1415-1428$

2. Reaven GM (1993) Role of insulin resistance in human disease (syndrome X) an expanded definition. Annu Rev Med 44: 121-131.

3. Kelly T, Yang W, Chen CS, Reynolds K, He J (2008) Global burden of obesity in 2005 and projections to 2030. Int J Obes (Lond) 32: 1431-1437.

4. vanDierenS, Beulens JW, van der Schouw YT, Grobbee DE, Neal B (2010) The global burden of diabetes and its complications: an emerging pandemic. Eur $\mathrm{J}$ Cardiovasc Prev Rehabil 17 Suppl 1: S3-8.

5. Nguyen DM, El-Serag HB (2010) The epidemiology of obesity. Gastroentero Clin North Am 39: 1-7.

6. de Carvalho Vidigal F, Bressan J, Babio N, Salas-Salvadó J1 (2013) Prevalence of metabolic syndrome in Brazilian adults: a systematic review. BMC Public Health 13: 1198 
Citation: Neto-Ferreira R, Rocha VN, de Carvalho JJ, Vilanova LC, Barbosa-da-Silva S, et al. (2014) Metabolic Syndrome: From Human Organ Disease to Fetal Programming. J Metabolic Synd 3: 133. doi:10.4172/2167-0943.1000133

7. Fantuzzi G (2005) Adipose tissue, adipokines, and inflammation. J Allergy Clin Immunol 115: 911-919.

8. Lettner A, Roden M (2008) Ectopic fat and insulin resistance. Curr Diab Rep 8: 185-191.

9. Aviram A, Hod M, Yogev Y (2011) Maternal obesity: implications for pregnancy outcome and long-term risks-a link to maternal nutrition. Int J Gynaecol Obstet 115 Suppl 1: S6-10.

10. Bruce KD, Cagampang FR (2011) Epigenetic priming of the metabolic syndrome. Toxicol Mech Methods 21: 353-361.

11. ShimabukuroM,Kozuka C, Taira S, Yabiku K, Dagvasumberel M, et al. (2013) Ectopic fat deposition and global cardiometabolic risk: new paradigm in cardiovascular medicine. J Med Invest 60: 1-14.

12. Li FY, Cheng KK, Lam KS, Vanhoutte PM, Xu A (2011) Cross-talk between adipose tissue and vasculature: role of adiponectin. Acta Physiol (Oxf) 203: 167-180.

13. Park HK, Ahima RS2 (2013) Resistin in rodents and humans. Diabetes Metab J 37: 404-414.

14. Ota T (2013) Chemokine systems link obesity to insulin resistance. Diabetes Metab J 37: 165-172

15. Colditz GA, Willett WC, Stampfer MJ, Manson JE, Hennekens CH, et al. (1990) Weight as a risk factor for clinical diabetes in women. Am J Epidemiol 132: 501-513

16. Wang ZM, Pierson RN Jr, Heymsfield SB (1992) The five-level model: a new approach to organizing body-composition research. Am J Clin Nutr 56: 19-28.

17. Arner $P$ (2005) Human fat cell lipolysis: biochemistry, regulation and clinical role. Best Pract Res Clin Endocrinol Metab 19: 471-482.

18. Skurk T, Alberti-Huber C, Herder C, Hauner H (2007) Relationship between adipocyte size and adipokine expression and secretion. J Clin Endocrino Metab 92: 1023-1033.

19. Samuel VT, Shulman GI (2012) Mechanisms for insulin resistance: common threads and missing links. Cell 148: 852-871.

20. Berge RK, Tronstad KJ, Berge K, Rost TH, Wergedahl H, et al. (2005) The metabolic syndrome and the hepatic fatty acid drainage hypothesis. Biochimie 87: $15-20$.

21. Mlinar B, Marc J, Janez A, Pfeifer M (2007) Molecular mechanisms of insulin resistance and associated diseases. Clin Chim Acta 375: 20-35.

22. Cavallo MG, Sentinelli F, Barchetta I, Costantino C, Incani M, et al. (2012) Altered glucose homeostasis is associated with increased serum apelin levels in type 2 diabetes mellitus. PLoS One 7: e51236.

23. Virtue S, Vidal-Puig A (2010) Adipose tissue expandability, lipotoxicity and the Metabolic Syndrome--an allostatic perspective. Biochim Biophys Acta 1801: 338-349.

24. Horowitz JF, Klein S (2000) Whole body and abdominal lipolytic sensitivity to epinephrine is suppressed in upper body obese women. Am J Physiol Endocrinol Metab 278: E1144-1152.

25. Trayhurn P, Wood IS (2004) Adipokines: inflammation and the pleiotropic role of white adipose tissue. Br J Nutr 92: 347-355.

26. Zamboni M, Rossi AP2, Fantin F2, Zamboni G3, Chirumbolo S2, et al. (2013) Adipose tissue, diet and aging. Mech Ageing Dev.

27. Bays HE (2009) "Sick fat," metabolic disease, and atherosclerosis. Am J Med 122: S26-37

28. Chandran M, Phillips SA, Ciaraldi T, Henry RR (2003) Adiponectin: more than just another fat cell hormone? Diabetes Care 26: 2442-2450.

29. Tilg H, Moschen AR (2006) Adipocytokines: mediators linking adipose tissue, inflammation and immunity. Nat Rev Immunol 6: 772-783.

30. Schulze MB, Rimm EB, Shai I, Rifai N, Hu FB (2004) Relationship between adiponectin and glycemic control, blood lipids, and inflammatory markers in men with type 2 diabetes. Diabetes Care 27: 1680-1687.

31. Fain JN, Madan AK, Hiler ML, Cheema P, Bahouth SW (2004) Comparison of the release of adipokines by adipose tissue, adipose tissue matrix, and adipocytes from visceral and subcutaneous abdominal adipose tissues of obese humans. Endocrinology 145: 2273-2282.
32. Gualillo O, González-Juanatey JR, Lago F (2007) The emerging role of adipokines as mediators of cardiovascular function: physiologic and clinical perspectives. Trends Cardiovasc Med 17: 275-283.

33. Bauche IB, El Mkadem SA, Pottier AM, Senou M, Many MC, et al. (2007) Overexpression of adiponectin targeted to adipose tissue in transgenic mice: impaired adipocyte differentiation. Endocrinology 148: 1539-1549.

34. Steppan CM, Bailey ST, Bhat S, Brown EJ, Banerjee RR, et al. (2001) The hormone resistin links obesity to diabetes. Nature 409: 307-312.

35. Nagaev I, Bokarewa M, Tarkowski A, Smith U (2006) Human resistin is a systemic immune-derived proinflammatory cytokine targeting both leukocytes and adipocytes. PLoS One 1: e31.

36. Patel L, Buckels AC, Kinghorn IJ, Murdock PR, Holbrook JD, et al. (2003) Resistin is expressed in human macrophages and directly regulated by PPAR gamma activators. Biochem Biophys Res Commun 300: 472-476.

37. Lazar MA (2007) Resistin- and Obesity-associated metabolic diseases. Horm Metab Res 39: 710-716.

38. Chen BH, Song Y, Ding EL, Roberts CK, Manson JE, et al. (2009) Circulating levels of resistin and risk of type 2 diabetes in men and women: results from two prospective cohorts. Diabetes Care 32: 329-334.

39. Friedman JM (1999) Leptin and the regulation of body weight. Harvey Lect 95 107-136.

40. Ahima RS, Flier JS (2000) Leptin. Annu Rev Physiol 62: 413-437.

41. Lee YH, Magkos F, Mantzoros CS, Kang ES (2011) Effects of leptin and adiponectin on pancreatic $\left.\right|^{2}$-cell function. Metabolism 60: 1664-1672.

42. Pick A, Clark J, Kubstrup C, Levisetti M, Pugh W, et al. (1998) Role of apoptosis in failure of beta-cell mass compensation for insulin resistance and beta-cell defects in the male Zucker diabetic fatty rat. Diabetes 47: 358-364.

43. Montague CT, Prins JB, Sanders L, Zhang J, Sewter CP, et al. (1998) Depotrelated gene expression in human subcutaneous and omental adipocytes. Diabetes 47: 1384-1391.

44. Yao-Borengasser A, Varma V, Bodles AM, Rasouli N, Phanavanh B, et al. (2007) Retinol binding protein 4 expression in humans: relationship to insulin resistance, inflammation, and response to pioglitazone. J Clin Endocrinol Metab 92: 2590-2597.

45. Yang Q, Graham TE, Mody N, Preitner F, Peroni OD, et al. (2005) Serum retinol binding protein 4 contributes to insulin resistance in obesity and type 2 diabetes. Nature 436: 356-362.

46. Graham TE, Yang Q, Blüher M, Hammarstedt A, Ciaraldi TP, et al. (2006) Retinol-binding protein 4 and insulin resistance in lean, obese, and diabetic subjects. N Engl J Med 354: 2552-2563.

47. Klöting N, Graham TE, Berndt J, Kralisch S, Kovacs P, et al. (2007) Serum retinol-binding protein is more highly expressed in visceral than in subcutaneous adipose tissue and is a marker of intra-abdominal fat mass. Cell Metab 6: 79 87.

48. Aeberli I, Biebinger R, Lehmann R, L'allemand D, Spinas GA, et al. (2007) Serum retinol-binding protein 4 concentration and its ratio to serum retinol are associated with obesity and metabolic syndrome components in children. J Clin Endocrinol Metab 92: 4359-4365.

49. Hotamisligil GS, Shargill NS, Spiegelman BM (1993) Adipose expression of tumor necrosis factor-alpha: direct role in obesity-linked insulin resistance. Science 259: 87-91.

50. Kanety H, Feinstein R, Papa MZ, Hemi R, Karasik A (1995) Tumor necrosis factor alpha-induced phosphorylation of insulin receptor substrate-1 (IRS1). Possible mechanism for suppression of insulin-stimulated tyrosine phosphorylation of IRS-1. J Biol Chem 270: 23780-23784.

51. Fève B, Bastard JP (2009) The role of interleukins in insulin resistance and type 2 diabetes mellitus. Nat Rev Endocrinol 5: 305-311.

52. Wellen KE, Hotamisligil GS (2003) Obesity-induced inflammatory changes in adipose tissue. J Clin Invest 112: 1785-1788.

53. Kanda H, Tateya S, Tamori Y, Kotani K, Hiasa K, et al. (2006) MCP-1 contributes to macrophage infiltration into adipose tissue, insulin resistance, and hepatic steatosis in obesity. J Clin Invest 116: 1494-1505.

54. Sartipy P, Loskutoff DJ (2003) Monocyte chemoattractant protein 1 in obesity and insulin resistance. Proc Natl Acad Sci U S A 100: 7265-7270. 
Citation: Neto-Ferreira R, Rocha VN, de Carvalho JJ, Vilanova LC, Barbosa-da-Silva S, et al. (2014) Metabolic Syndrome: From Human Organ Disease to Fetal Programming. J Metabolic Synd 3: 133. doi:10.4172/2167-0943.1000133

55. Tatemoto K, Takayama K, Zou MX, Kumaki I, Zhang W, et al. (2001) The novel peptide apelin lowers blood pressure via a nitric oxide-dependent mechanism. Regul Pept 99: 87-92.

56. Boucher J, Masri B, Daviaud D, Gesta S, Guigné C, et al. (2005) Apelin, a newly identified adipokine up-regulated by insulin and obesity. Endocrinology 146: $1764-1771$

57. Castan-Laurell I, Dray C, Attané C, Duparc T, Knauf C, et al. (2011) Apelin, diabetes, and obesity. Endocrine 40: 1-9.

58. Neto-Ferreira R, Rocha VN, Souza-Mello V, Mandarim-de-Lacerda CA de Carvalho JJ (2013) Pleiotropic effects of rosuvastatin on the glucose metabolism and the subcutaneous and visceral adipose tissue behavior in C57BI/6 mice. Diabetol Metab Syndr 5: 32.

59. Fraulob JC, Souza-Mello V, Aguila MB, Mandarim-de-Lacerda CA (2012) Beneficial effects of rosuvastatin on insulin resistance, adiposity, inflammatory markers and non-alcoholic fatty liver disease in mice fed on a high-fat diet. Clin Sci (Lond) 123: 259-270.

60. Ip BC, Wang XD2 (2013) Non-alcoholic steatohepatitis and hepatocellular carcinoma: implications for lycopene intervention. Nutrients 6: 124-162.

61. Fruci B, Giuliano S, Mazza A, Malaguarnera R, Belfiore A (2013) Nonalcoholic Fatty liver: a possible new target for type 2 diabetes prevention and treatment. Int J Mol Sci 14: 22933-22966.

62. Zhang W, Wu R, Zhang F, Xu Y, Liu B, et al. (2012) Thiazolidinediones improve hepatic fibrosis in rats with non-alcoholic steatohepatitis by activating the adenosine monophosphate-activated protein kinase signalling pathway. Clin Exp Pharmacol Physiol 39: 1026-1033.

63. Souza-Mello V, Gregório BM, Cardoso-de-Lemos FS, de Carvalho L, Aguila MB, et al. (2010) Comparative effects of telmisartan, sitagliptin and metformin alone or in combination on obesity, insulin resistance, and liver and pancreas remodelling in C57BL/6 mice fed on a very high-fat diet. Clin Sci (Lond) 119 239-250.

64. Yki-Järvinen H (2004) Thiazolidinediones. N Engl J Med 351: 1106-1118.

65. Gurnell M, Savage DB, Chatterjee VK, O'Rahilly S (2003) The metabolic syndrome: peroxisome proliferator-activated receptor gamma and its therapeutic modulation. J Clin Endocrinol Metab 88: 2412-2421.

66. Mohanty P, Aljada A, Ghanim H, Hofmeyer D, Tripathy D, et al. (2004) Evidence for a potent antiinflammatory effect of rosiglitazone. J Clin Endocrinol Metab 89: $2728-2735$

67. Barnett A (2006) DPP-4 inhibitors and their potential role in the management of type 2 diabetes. Int J Clin Pract 60: 1454-1470.

68. Ginsberg LD (2006) Efficacy and safety of lamotrigine for adults with bipolar disorder in a private practice setting. CNS Spectr 11: 376-382.

69. Rosenson RS (2003) Rosuvastatin: a new inhibitor of HMG-coAreductase for the treatment of dyslipidemia. Expert Rev Cardiovasc Ther 1: 495-505.

70. McTaggart F (2003) Comparative pharmacology of rosuvastatin. Atheroscler Suppl 4: 9-14.

71. Neto-Ferreira R, Novaes Rocha V, da Silva Torres T, Mandarim-de-Lacerda CA, de Carvalho JJ (2011) Beneficial effects of rosuvastatin on aortic adverse remodeling in nitric oxide-deficient rats. Exp Toxicol Pathol 63: 473-478.

72. Hézode C, Roudot-Thoraval F, Nguyen S, Grenard P, Julien B, et al. (2005) Daily cannabis smoking as a risk factor for progression of fibrosis in chronic hepatitis C. Hepatology 42: 63-71.

73. Janero DR, Lindsley L, Vemuri VK, Makriyannis A (2011) Cannabinoid 1 G protein-coupled receptor (periphero-)neutral antagonists: emerging therapeutics for treating obesity-driven metabolic disease and reducing cardiovascular risk. Expert Opin Drug Discov 6: 995-1025.

74. Tahara A, Kurosaki E, Yokono M, Yamajuku D, Kihara R, et al. (2013) Effects of SGLT2 selective inhibitor ipragliflozin on hyperglycemia, hyperlipidemia, hepatic steatosis, oxidative stress, inflammation, and obesity in type 2 diabetic mice. Eur J Pharmacol 715: 246-255.

75. Liu L, Miura K, Fujiyoshi A, Kadota A, Miyagawa N, et al. (2014) Impact of metabolic syndrome on the risk of cardiovascular disease mortality in the United States and in Japan. Am J Cardiol 113: 84-89.

76. Novelletto BF, Guzzinati S, Avogaro A (2012) Prevalence of metabolic syndrome and its relationship with clinically prevalent cardiovascular disease in the Veneto region, northeastern Italy. Metab Syndr Relat Disord 10: 56-62.
77. Gami AS, Witt BJ, Howard DE, Erwin PJ, Gami LA, et al (2007) Metabolic syndrome and risk of incident cardiovascular events and death: a systematic review and meta-analysis of longitudinal studies. J Am Coll Cardiol 49: 403-414

78. Roberts AW, Clark AL, Witte KK (2009) Review article: Left ventricular dysfunction and heart failure in metabolic syndrome and diabetes without overt coronary artery disease--do we need to screen our patients? Diab Vasc Dis Res 6: 153-163.

79. Wang Y, Yu Q, Chen Y, Cao F (2013) Pathophysiology and therapeutics of cardiovascular disease in metabolic syndrome. Curr Pharm Des 19: 47994805 .

80. Thomsen M, Nordestgaard BG (2014) Myocardial infarction and ischemic heart disease in overweight and obesity with and without metabolic syndrome. JAMA Intern Med 174: 15-22.

81. Tadic M, Ivanovic B, Cuspidi C (2013) Metabolic syndrome and right ventricle: an updated review. Eur J Intern Med 24: 608-616.

82. Di Lorenzo C, Dell'agli M, Colombo E, Sangiovanni E, Restani P (2013) Metabolic syndrome and inflammation: a critical review of in vitro and clinical approaches for benefit assessment of plant food supplements. Evid Based Complement Alternat Med 2013: 782461.

83. Fuentes E, Guzmán-Jofre L, Moore-Carrasco R, Palomo I (2013) Role of PPARs in inflammatory processes associated with metabolic syndrome (Review). Mol Med Rep 8: 1611-1616.

84. Clearfield M, Pearce M, Nibbe Y, Crotty D, Wagner A (2014) The "New Deadly Quartet" for cardiovascular disease in the 21st century: obesity, metabolic syndrome, inflammation and climate change: how does statin therapy fit into this equation? Curr Atheroscler Rep 16: 380

85. Asrih M, Mach F, Nencioni A, Dallegri F, Quercioli A, et al. (2013) Role of mitogen-activated protein kinase pathways in multifactorial adverse cardiac remodeling associated with metabolic syndrome. Mediators Inflamm 2013 367245 .

86. Li ZL, Woollard JR, Ebrahimi B, Crane JA, Jordan KL, et al. (2012) Transition from obesity to metabolic syndrome is associated with altered myocardial autophagy and apoptosis. Arterioscler Thromb Vasc Biol 32: 1132-1141.

87. Ilkun O, Boudina S (2013) Cardiac dysfunction and oxidative stress in the metabolic syndrome: an update on antioxidant therapies. Curr Pharm Des 19 4806-4817.

88. Abel ED, Litwin SE, Sweeney G (2008) Cardiac remodeling in obesity. Physio Rev 88: 389-419.

89. Mandavia CH1, Aroor AR, Demarco VG, Sowers JR (2013) Molecular and metabolic mechanisms of cardiac dysfunction in diabetes. Life Sci 92: 601-608.

90. Sharma N, Okere IC, Duda MK, Chess DJ, O'Shea KM, et al. (2007) Potential impact of carbohydrate and fat intake on pathological left ventricular hypertrophy. Cardiovasc Res 73: 257-268.

91. Mendizábal Y, Llorens S, Nava E (2013) Hypertension in metabolic syndrome: vascular pathophysiology. Int J Hypertens 2013: 230868.

92. Dikalov SI, Nazarewicz RR (2013) Angiotensin II-induced production of mitochondrial reactive oxygen species: potential mechanisms and relevance for cardiovascular disease. Antioxid Redox Signal 19: 1085-1094.

93. Zhou MS, Schulman IH, Zeng Q (2012) Link between the renin-angiotensin system and insulin resistance: implications for cardiovascular disease. Vasc Med 17: 330-341.

94. Patel KP, Schultz HD (2013) Angiotensin peptides and nitric oxide in cardiovascular disease. Antioxid Redox Signal 19: 1121-1132.

95. Markowitz M, Messineo F, Coplan NL (2012) Aldosterone receptor antagonists in cardiovascular disease: a review of the recent literature and insight into potential future indications. Clin Cardiol 35: 605-609.

96. He BJ, Anderson ME (2013) Aldosterone and cardiovascular disease: the heart of the matter. Trends Endocrinol Metab 24: 21-30.

97. Lopaschuk GD, Ussher JR, Folmes CD, Jaswal JS, Stanley WC (2010) Myocardial fatty acid metabolism in health and disease. Physiol Rev 90: 207

98. Stanley WC, Dabkowski ER, Ribeiro RF Jr, O'Connell KA (2012) Dietary fat and heart failure: moving from lipotoxicity to lipoprotection. Circ Res 110: 764-776.

99. Boudina S, Abel ED (2010) Diabetic cardiomyopathy, causes and effects. Rev Endocr Metab Disord 11: 31-39. 
Citation: Neto-Ferreira R, Rocha VN, de Carvalho JJ, Vilanova LC, Barbosa-da-Silva S, et al. (2014) Metabolic Syndrome: From Human Organ Disease to Fetal Programming. J Metabolic Synd 3: 133. doi:10.4172/2167-0943.1000133

100. Sack M (2002) Tumor necrosis factor-alpha in cardiovascular biology and the potential role for anti-tumor necrosis factor-alpha therapy in heart disease. Pharmacol Ther 94: 123-135.

101. Ferrari R (1999) The role of TNF in cardiovascular disease. Pharmacol Res 40: $97-105$

102. Korkmaz GG, AltÄ \pm noglu E, Civelek S, Sozer V, Erdenen F, et al. (2013) The association of oxidative stress markers with conventional risk factors in the metabolic syndrome. Metabolism 62: 828-835.

103. Fernandez-Garcia JC, Cardona F, Tinahones FJ1 (2014) Inflammation, oxidative stress and metabolic syndrome: dietary modulation. Curr Vasc Pharmacol 11: 906-919.

104. Yubero-Serrano EM, Delgado-Lista J, Peña-Orihuela $P$, Perez-Martinez $P$, Fuentes F, et al. (2013) Oxidative stress is associated with the number of components of metabolic syndrome: LIPGENE study. Exp Mol Med 45: e28.

105.Ren J, Pulakat L, Whaley-Connell A, Sowers JR (2010) Mitochondrial biogenesis in the metabolic syndrome and cardiovascular disease. J Mol Med (Berl) 88: 993-1001.

106. Bugger $\mathrm{H}$, Abel ED (2008) Molecular mechanisms for myocardial mitochondrial dysfunction in the metabolic syndrome. Clin Sci (Lond) 114: 195-210.

107.Elnakish MT, Hassanain HH, Janssen PM, Angelos MG, Khan M (2013) Emerging role of oxidative stress in metabolic syndrome and cardiovascular diseases: important role of Rac/NADPH oxidase. J Pathol 231: 290-300.

108. Marín-García J, Akhmedov AT, Moe GW (2013) Mitochondria in heart failure: the emerging role of mitochondrial dynamics. Heart Fail Rev 18: 439-456.

109. Rosca MG, Tandler B, Hoppel CL (2013) Mitochondria in cardiac hypertrophy and heart failure. J Mol Cell Cardiol 55: 31-41.

110. Rosca MG, Hoppel CL (2013) Mitochondrial dysfunction in heart failure. Heart Fail Rev 18: 607-622.

111. Bayeva M, Gheorghiade M, Ardehali H (2013) Mitochondria as a therapeutic target in heart failure. J Am Coll Cardiol 61: 599-610.

112. Balderas-Villalobos J, Molina-Muñoz T, Mailloux-Salinas P, Bravo G, Carvajal $\mathrm{K}$, et al. (2013) Oxidative stress in cardiomyocytes contributes to decreased SERCA2a activity in rats with metabolic syndrome. Am J Physiol Heart Circ Physiol 305: H1344-1353.

113. Weiss TW, Arnesen H, Seljeflot I (2013) Components of the interleukin-6 transsignalling system are associated with the metabolic syndrome, endothelial dysfunction and arterial stiffness. Metabolism 62: 1008-1013.

114. Zambon A, Pauletto P, Crepaldi G (2005) Review article: the metabolic syndrome--a chronic cardiovascular inflammatory condition. Aliment Pharmacol Ther 22 Suppl 2: 20-23.

115. Ellison RC, Zhang Y, Wagenknecht LE, Eckfeldt JH, Hopkins PN, et al. (2005) Relation of the metabolic syndrome to calcified atherosclerotic plaque in the coronary arteries and aorta. Am J Cardiol 95: 1180-1186.

116. Ohnuki T, Takahashi W, Ohnuki Y, Kawada S, Takizawa S (2013) Significance of the presence of metabolic syndrome in patients with asymptomatic arteriosclerosis affecting the aorta and the cerebral, extra-cranial carotid and coronary arteries. Intern Med 52: 523-527.

117. Tesauro M, Cardillo C (2011) Obesity, blood vessels and metabolic syndrome. ActaPhysiol (Oxf) 203: 279-286.

118. Stepp DW, Pollock DM, Frisbee JC (2004) Low-flow vascular remodeling in the metabolic syndrome X. Am J Physiol Heart Circ Physiol 286: H964-970.

119. Kuliszewski MA, Ward MR, Kowalewski JW, Smith AH, Stewart DJ, et al. (2013) A direct comparison of endothelial progenitor cell dysfunction in rat metabolic syndrome and diabetes. Atherosclerosis 226: 58-66.

120. Alexandraki KI, Kaltsas GA (2013) Endocrinopathies and other disorders inducing a polycystic ovary syndrome phenotype. Front Horm Res 40: 142157.

121. March WA, Moore VM, Willson KJ, Phillips DI, Norman RJ, et al. (2010) The prevalence of polycystic ovary syndrome in a community sample assessed under contrasting diagnostic criteria. Hum Reprod 25: 544-551.

122. Alvarez-Blasco F, Botella-Carretero JI, San Millán JL, Escobar-Morreale HF (2006) Prevalence and characteristics of the polycystic ovary syndrome in overweight and obese women. Arch Intern Med 166: 2081-2086.

123. Huang G, Coviello A (2012) Clinical update on screening, diagnosis and management of metabolic disorders and cardiovascular risk factors associated with polycystic ovary syndrome. Curr Opin Endocrinol Diabetes Obes 19: 512519.

124. Baranova A, Tran TP, Birerdinc A, Younossi ZM (2011) Systematic review: association of polycystic ovary syndrome with metabolic syndrome and nonalcoholic fatty liver disease. Aliment Pharmacol Ther 33: 801-814.

125. Kiddy DS, Sharp PS, White DM, Scanlon MF, Mason HD, et al. (1990) Differences in clinical and endocrine features between obese and non-obese subjects with polycystic ovary syndrome: an analysis of 263 consecutive cases. Clin Endocrinol (Oxf) 32: 213-220.

126. Silfen ME, Denburg MR, Manibo AM, Lobo RA, Jaffe R, et al. (2003) Early endocrine, metabolic, and sonographic characteristics of polycystic ovary syndrome (PCOS): comparison between nonobese and obese adolescents. $\mathrm{J}$ Clin Endocrinol Metab 88: 4682-4688.

127. Bollag GE, Roth RA, Beaudoin J, Mochly-Rosen D, Koshland DE Jr (1986) Protein kinase $C$ directly phosphorylates the insulin receptor in vitro and reduces its protein-tyrosine kinase activity. Proc Natl AcadSci U S A 83: 5822 5824

128. Takayama S, White MF, Kahn CR (1988) Phorbol ester-induced serine phosphorylation of the insulin receptor decreases its tyrosine kinase activity. $J$ Biol Chem 263: 3440-3447.

129. Jialal I, Naiker P, Reddi K, Moodley J, Joubert SM (1987) Evidence for insulin resistance in nonobese patients with polycystic ovarian disease. J Clin Endocrinol Metab 64: 1066-1069.

130. Bremer AA (2010) Polycystic ovary syndrome in the pediatric population Metab Syndr RelatDisord 8: 375-394.

131. Abbott DH, Barnett DK, Bruns CM, Dumesic DA (2005) Androgen excess feta programming of female reproduction: a developmental aetiology for polycystic ovary syndrome? Hum Reprod Update 11: 357-374.

132. Abbott DH, Tarantal AF, Dumesic DA (2009) Fetal, infant, adolescent and adult phenotypes of polycystic ovary syndrome in prenatally androgenized female rhesus monkeys. Am J Primatol 71: 776-784.

133.Zhou R, Bird IM, Dumesic DA, Abbott DH (2005) Adrenal hyperandrogenism is induced by fetal androgen excess in a rhesus monkey model of polycystic ovary syndrome. J Clin Endocrinol Metab 90: 6630-6637.

134. Ibáñez L, Dimartino-Nardi J, Potau N, Saenger P (2000) Premature adrenarche--normal variant or forerunner of adult disease? Endocr Rev 21 : 671-696.

135. Bates GW, Legro RS (2013) Longterm management of Polycystic Ovarian Syndrome (PCOS). Mol Cell Endocrinol 373: 91-97.

136. Gangale MF, Miele L, Lanzone A, Sagnella F, Martinez D et al. (2011) Longterm metformin treatment is able to reduce the prevalence of metabolic syndrome and its hepatic involvement in young hyperinsulinaemic overweigh patients with polycystic ovarian syndrome. Clin Endocrinol (Oxf). 75: 520-527.

137. Genazzani AD, Ricchieri F, Lanzoni C (2010) Use of metformin in the treatment of polycystic ovary syndrome. Womens Health (LondEngl) 6: 577-593.

138. Pugeat M, Ducluzeau PH (1999) Insulin resistance, polycystic ovary syndrome and metformin. Drugs 58 Suppl 1: 41-46.

139. Velazquez EM, Mendoza S, Hamer T, Sosa F, Glueck CJ (1994) Metformin therapy in polycystic ovary syndrome reduces hyperinsulinemia, insulin resistance, hyperandrogenemia, and systolic blood pressure, while facilitating normal menses and pregnancy. Metabolism 43: 647-654.

140.Bouchard C (1997) Obesity in adulthood--the importance of childhood and parental obesity. N Engl J Med 337: 926-927.

141.Denison FC, Roberts KA, Barr SM, Norman JE (2010) Obesity, pregnancy, inflammation, and vascular function. Reproduction 140: 373-385.

142. Gallou-Kabani C, Vigé A, Gross MS, Boileau C, Rabes JP, et al. (2007) Resistance to high-fat diet in the female progeny of obese mice fed a contro diet during the periconceptual, gestation, and lactation periods. Am J Physiol Endocrinol Metab 292: E1095-1100.

143. Sullivan EL, Grove KL (2010) Metabolic imprinting in obesity. Forum Nutr 63 186-194.

144. Howie GJ1, Sloboda DM, Kamal T, Vickers MH (2009) Maternal nutritional history predicts obesity in adult offspring independent of postnatal diet. $J$ Physiol 587: 905-915. 
Citation: Neto-Ferreira R, Rocha VN, de Carvalho JJ, Vilanova LC, Barbosa-da-Silva S, et al. (2014) Metabolic Syndrome: From Human Organ Disease to Fetal Programming. J Metabolic Synd 3: 133. doi:10.4172/2167-0943.1000133

Page 10 of 10

145. Drake AJ, Reynolds RM (2010) Impact of maternal obesity on offspring obesity and cardiometabolic disease risk. Reproduction 140: 387-398.

146. McCurdy CE, Bishop JM, Williams SM, Grayson BE, Smith MS, et al. (2009) Maternal high-fat diet triggers lipotoxicity in the fetal livers of nonhuman primates. J Clin Invest 119: 323-335.

147. Fernandez-Twinn DS, Ozanne SE (2010) Early life nutrition and metabolic programming. Ann N Y AcadSci 1212: 78-96.

148. Lucas A (1991) Programming by early nutrition in man. Ciba Found Symp 156 38-50.

149.Barker DJ, Osmond C (1986) Infant mortality, childhood nutrition, and ischaemic heart disease in England and Wales. Lancet 1: 1077-1081.

150. Taylor PD, Poston L (2007) Developmental programming of obesity in mammals. Exp Physiol 92: 287-298.

151. Samuelsson AM, Matthews PA, Argenton M, Christie MR, McConnell JM, et al. (2008) Diet-induced obesity in female mice leads to offspring hyperphagia, adiposity, hypertension, and insulin resistance: a novel murine model of developmental programming. Hypertension 51: 383-392.

152. Bouret SG (2009) Early life origins of obesity: role of hypothalamic programming. J Pediatr Gastroenterol Nutr 48 Suppl 1: S31-38.

153. Ornellas F, Mello VS, Mandarim-de-Lacerda CA, Aguila MB (2013) Sexual dimorphism in fat distribution and metabolic profile in mice offspring from dietinduced obese mothers. Life Sci 93: 454-463.

154.Brüning JC, Gautam D, Burks DJ, Gillette J, Schubert M, et al. (2000) Role of brain insulin receptor in control of body weight and reproduction. Science 289: $2122-2125$.

155. Vickers MH, Reddy S, Ikenasio BA, Breier BH (2001) Dysregulation of the adipoinsular axis -- a mechanism for the pathogenesis of hyperleptinemia and adipogenic diabetes induced by fetal programming. J Endocrinol 170: 323332.

156. Cerf ME (2010) High fat programming of beta-cell failure. Adv Exp Med Bio 654: $77-89$
157. Gniuli D, Calcagno A, Caristo ME, Mancuso A, Macchi V, et al. (2008) Effects of high-fat diet exposure during fetal life on type 2 diabetes development in the progeny. J Lipid Res 49: 1936-1945.

158. Gregorio BM, Souza-Mello V, Mandarim-de-Lacerda CA, Aguila MB (2013) Maternal high-fat diet is associated with altered pancreatic remodelling in mice offspring. Eur J Nutr 52: 759-769.

159. Cerf ME, Chapman CS, Muller CJ, Louw J (2009) Gestational highfat programming impairs insulin release and reduces $\mathrm{Pdx}-1$ and glucokinaseimmunoreactivity in neonatal Wistar rats. Metabolism 58: 17871792.

160. Aerts L, Van Assche FA (2006) Animal evidence for the transgenerational development of diabetes mellitus. Int J Biochem Cell Biol 38: 894-903.

161. Fall C (2009) Maternal nutrition: effects on health in the next generation. Indian J Med Res 130: 593-599.

162. Reusens B, Theys N, Dumortier O, Goosse K, Remacle C (2011) Maternal malnutrition programs the endocrine pancreas in progeny. Am J Clin Nutr 94: 1824S-1829S.

163. Oben JA, Mouralidarane A, Samuelsson AM, Matthews PJ, Morgan ML, et al. (2010) Maternal obesity during pregnancy and lactation programs the development of offspring non-alcoholic fatty liver disease in mice. $\mathrm{J}$ Hepatol 52: 913-920.

164. Aguila MB, Fernandes-Santos C, Pinheiro-Mulder AR, Faria TS, Mandarimde-Lacerda CA (2010) Hepatic insulin resistance and nonalcoholic fatty liver disease. In: Molière J, Gauthier L (Eds.), Insulin resistance: symptons, causes and treatment. Hauppauge, Nova Science Pu., New York, pp: 1-44.

165. Gregorio BM, Souza-Mello V, Carvalho JJ, Mandarim-de-Lacerda CA, Aguila MB (2010) Maternal high-fat intake predisposes nonalcoholic fatty liver disease in C57BL/6 offspring. Am J Obstet Gynecol 203: 495.

166. Magliano DC, Bargut TC, de Carvalho SN, Aguila MB, Mandarim-de-Lacerda CA, et al. (2013) Peroxisome proliferator-activated receptors-alpha and gamma are targets to treat offspring from maternal diet-induced obesity in mice. PLOS One 8: e64258. 